\title{
A Public Sector Comparator (PSC) for Value for Money (VFM) Assessment Tools
}

\author{
Kharizam Ismail $^{1}$, Roshana Takim ${ }^{1} \&$ Abdul Hadi Nawawi ${ }^{1}$ \\ ${ }^{1}$ Centre of Postgraduate Studies, Faculty of Architecture, Planning and Surveying, Universiti Teknologi MARA \\ (UiTM), Shah Alam, Malaysia \\ Correspondence: Kharizam Ismail, Centre of Postgraduate Studies, Faculty of Architecture, Planning and \\ Surveying, Universiti Teknologi MARA (UiTM), 40450 Shah Alam, Selangor, Malaysia. E-mail: \\ khari511@yahoo.com
}

Received: January 12, $2012 \quad$ Accepted: March 19, $2012 \quad$ Published: June 1, 2012

doi:10.5539/ass.v8n7p192 URL: http://dx.doi.org/10.5539/ass.v8n7p192

\begin{abstract}
In a generic sense, when procuring Public Private Partnership (PPP) projects, value for money (VFM) assessment could be determined through a comparative analysis of contractors' proposals against Public Sector Comparator (PSC) documentation. A PSC is a hypothetical framework used as a procurement strategy tool in evaluating VFM and has been a trademark for most countries across the globe such as UK, Australia, Hong Kong and Canada. However, this strategy has not been systematically formulated and applied in Malaysia. The probable reasons for this predicament could be due to the controversy in risk calculation; lacking of nonfinancial aspects and future cash flow, inappropriate discounted rate used and the difficulty in the PSC calculation. Hence, the aim of this study is to ascertain a complete PSC framework for PPP projects embracing financial and non-financial aspects across project phases (i.e., strategy formulation; procurement; construction and operation phase). The empirical research via questionnaire survey was conducted among PPP stakeholders. The results indicated that the development of PSC framework would facilitate a comprehensive dimension of VFM evaluation for PPP projects in Malaysia.
\end{abstract}

Keywords: public sector comparator (PSC), public private partnership (PPP), value for money (VFM), financial and non- financial factors

\section{Introduction}

Today's competitive global environment has led governments around the world to seek new ways to finance and build government's projects. Hence, a Public Private Partnership (PPP) concept is increasingly favoured globally as a tool to exploit the strengths of the private sectors to facilitate as opposed to the conventional system. Theoretically, there are many reasons behind the prompting for a PPP implementation. Literature source on PPP scrutinised the issues of value for money (VFM), risk transfer, innovation, stimulating economic growth and enhancing the quality of public projects as among the attractive factors under PPP regime. Nevertheless, the VFM matter is at the forefront of most government's agenda and is therefore expected as a benefit of this approach.

The gist term of VFM is wide-ranging and captures the issues of whole life cost, benefits, risk and quality to achieve the desired results in accordance with the clients' requirements. In a generic sense, VFM will be determined through a comparative analysis of PPP proposals by private sectors against a public sector alternative by means of Public Sector Comparator (PSC). Public sector Comparator is a hypothetical benchmark that stands for the whole of life cost and risk adjusted of public sector provision as defined in the UK green book and the Australian government. Though the definition differs from each other to some extent, the key elements of PSC include the following aspects: hypothetical and a forecast; net present value number based on life cycle costing; risk adjusted and the possibility that the public sector is to deliver. The purpose of PSC is to assist in decision making by testing whether a private investment proposal offers better VFM in comparison with the most efficient form of public procurement.

Practically many countries namely UK, South Africa, Australia, Hong Kong and Netherland are representative countries applying PSC in evaluating VFM of the Public Private Partnership (PPP) projects. However, this 
concept literally has not been applied in Malaysia. Even though this had been highlighted in the Ninth Malaysia plan (2006), the establishment of PSC guideline is yet to be established. In the other hands, there are the significant challenges in the development of PSC (Pangera \& Wirahadikusumah, 2010) due to controversy concerning manipulation issues, risk calculation and lacking of non financial elements. Besides, the application of PSC in VFM assessment process has been criticized on numerous grounds of issues by the practitioners. Some of the issues rely on: deficient of non financial aspects for instance social and environmental benefit; the accuracy of the risk calculation, assumption and discount rate used in financial calculation. For example: since the discounting inherent in calculating NPV, even small changes in discount rate applied will vary the outcome of the VFM. Joaquim (2010), critiques the PSC is tend to manipulation because the government authority wants to prove VFM by exaggeration innovation and benefits of a PPP option. Thus, the PSC frequently underestimated the full cost of the PPP option and it will present the PSC as an invention, artificial and biased.

In the case of Malaysia, these challenges are due to the lacking in compilation of data base for whole life cycle of projects specifically on the prediction of future operation, maintenance cost and risk calculation. The fact of the matter is that the Malaysia PPP projects also lack sufficient information to make more predictable assumption to all the stakeholders involved, since it is a relatively new method in Malaysia. Practically, the Malaysia PPP procurement authority tends to utilize a common project evaluation method that ignores the issues of risk calculation and whole life cycle concept. Due to a lack of research that explains on elements that are required in each stage of a VFM assessment, therefore, this study is purely based on VFM guidelines from various countries. Guidelines from the UK, Australia (Queensland), South Africa, Partnership British Colombia and Ireland are used to obtain a clearer picture of VFM process. This could serve as references on elements that should be applied for the development process for a robust VFM assessment in Malaysia. Basically the four guidelines (i.e., UK, Queensland, South Africa and Ireland) have identified as three stages of VFM assessment process. These include: programme; project and procurement level assessment. Primarily, PSC is used to compare issues related to the financial aspects. The non-financial aspects embrace the elements of: risk management; project level objectives; innovation solution; flexibility of operation; anticipated of users benefits; incentives and monitoring; facilities management services; public interest consideration, life cycle cost, market interest and sustainability requirements (HM Treasury, 2006; Partnership British Colombia,2005; Queensland Government, 2008).

Most countries (except the UK guideline) do not postulate clearly elements for a VFM assessment process at each stage of a project life cycle. Khadaroo (2008) and Broadbent (2002) are among some researchers who agree to have a complete guideline that specifies all elements necessary for each stage of a PPP lifecycle. Hence, based on this notion, the aim of the study is to develop a comprehensive of VFM assessment tool embracing the four stage of project lifecycle (strategy formulation, procurement, construction and completion) and to enlighten the core components (financial and non-financial) of PSC as a VFM assessment tool. It is vital that a complete VFM assessment requires consideration of non-financial factors and long term evaluation in conjunction with the financial assessment.

\subsection{Public Sector Comparator (PSC)}

Numerous definitions of Public Sector Comparator (PSC) abound in the academic literature. Theoretically, Public Sector Comparator is a hypothetical benchmark stands for the cost of public sector provision. Although similar PSC features seem appear across the countries there are several differences in the principal and definition of these terms. Some difference for instance terminologies may differ, for instance Ireland's Central PPP unit calls this same as a Public Sector Benchmark (PSB). While, in Texas the development of PSC is known as market valuation. The Ireland Central Unit PPP (2007), Australia Victoria Partnership (2006), Hong Kong PPP guide (2006) and National Treasury PPP, South Africa (2004); have the similar views of the PSC definition. They described PSC as an estimate of the hypothetical whole life cost, risk and benefit of a public sector in delivering the project by using traditional approach. While, English \& Guthrie (2003), are more optimistic in describing PSC as an estimated reference project to provide the same level and quality of service expected of the private sector alternatives.

Though these definitions differ from each other to some extent, however, all these are relatively similar in that the key elements of PSC include the following aspects: hypothetical and a forecast; net present value number based on life cycle costing; risk adjusted and the possibility that the public sector is to deliver. Basically, PSC facilitates a financial comparison including costs, benefits and risks. Based on the literature, it can be deduced that PSC are generally categorized into four components (Joaquim, 2010, Hui et al. 2010 and Morallos et al. 2009). The four components start with 'raw PSC (capital and operating cost). Raw PSC deals with the base cost of delivering the services specified in the project brief under the public procurement method. It includes all 
capital, operating costs associated with building, owning, maintaining and delivering the service over the pre determined time. Secondly, is the competitive neutrality which concerns with the cost adjustment to remove any net competitive advantages that accrues to a government business (i.e., the nonpayment of insurance premium or taxes by a government). Thirdly, is the transferable risk which deals with the value of risks in which the government would transfer to the private sector (example: design and construction, operating, maintenance and technology risks). Fourthly, is related to retained risk which is the value of any risk that is not transferred to the bidder.

Using the information derived from the review of PSC models from Hong Kong, South Africa, Ireland and Australia, important elements are captured. The PSC of Hong Kong provides a basis of comparison between PPP and the public sector alternatives based on four (4) fundamental elements: i.e.: raw PSC, competitive neutrality, transferable and retained risk. The quantitative assessment is underlined as core criteria in PSC calculation. Nevertheless, this model is lacking in many important elements such as qualitative and long term aspects. The South Africa model offers a near complete and ample process outlined in PSC calculations. All the processes involved are spelled out clearly and comprehensively. However the model is less focussed on the discount rate and appropriate assumption aspects such as identification of risk and inflation rate. Meanwhile, the Ireland PSC model (known as PSB) seems to be broad and extensive which takes into consideration the full estimated costs, income and risks as key components of PSB. Nevertheless, once again the PSB model failed to consider further the qualitative and long term aspects. Among others, the Australia PSC model is the most applicable to be adopted and practiced in the assessment of VFM. The model commences based on two crucial assessments: qualitative and quantitative aspects. All the process involved such as discount rate, components in PSC calculation, major assumption and qualitative aspects are clearly specified. Conversely, this model fails to discuss assessment of VFM during construction and operation phase which are paramount to a complete VFM assessment. This could be due to the difficulty in specifying outputs specification in long term requirements and obtaining the future data for cost estimate.

The literary source perused in the application of PSC can be helpful in providing: method for demonstrating VFM; whole life costing early in the project's development; assessing the affordability of a project; encouraging bidding competition; management of risk and as a benchmark for evaluation tool. Grimsey and Lewis (2005), noted the objectives development of PSC are: firstly, to promote full costing at an early stage; secondly, provide a key management tool during the procurement process by focusing attention on the output specification, risk allocation and comprehensive costing and finally, to provide a consistent benchmark and evaluation tool. As practiced in the UK and Australia, PSC is constructed and refined during the feasibility and business case stages. Basically, the purpose of using PSC by the government is to make decisions by testing whether a private investment proposal offers better VFM in comparison with the most efficient form of public procurement. Generally, PSC aims to provide a reference point for comparing the cost of public delivery of infrastructure with other procurement methods. From the public perspective, PSC has a role in the process of achieving public confidence in development of the projects. Meanwhile, the bidder's perspective opined PSC is a benchmark for design quality, space requirements, quality of materials and environmental system. Therefore, it can be said that the role of PSC is to ensure that the resource of the private sector are used efficiently and effectively for specifying project requirements.

However, despite its well recognised urgency, from analyses it appears that the use of the PSC has been criticised by practitioners and researcher. These criticisms can be segregated into numerous categories. For example, Kristiansen (2009) argue that PSC tends to be manipulated by the exaggeration of innovation and limited scope for efficiency improvements in the public projects. Leighland \& Shugart (2006) criticised the lack of standard method for identifying and measuring values of risk in PSC calculation. They highlighted that the methodology of risk calculation is conceptually flawed and problematic because all possible outcome cannot be predicted and weighted. Generally, the risk calculation depends upon the ability to attach probabilities and value values to a range of outcomes. However, the process is inevitably subjective and unpredictable given the lack sound prior evidence to base of estimates.

While, other commentators noted that PSC may not take into account indirect cost such as monitoring cost, assumption of discount rate and inherent limitation of revenue forecast over the life of the proposed contract period. Khadaroo (2008) and Ismail \& Pendlebury (2006) reckon that PSC does not provide any possibilities for accurate estimates for costs in the construction and operation evaluation stages. There are also arguments on restricted scope of PSC expressed in the domination of financial aspects only. From the literature analysis point of view, this method is mainly focused on the financial approach and had been noted that there is lack of consideration on non-financial aspects in the PSC calculation Although the financial assessment constitutes a 
significant portion of the VFM analysis, many agencies place equal importance on the non-financial factors that affect VFM. A non-financial assessments should be conducted in order to generate insights whether the project are progressing to highlight any problem encountered. For example, the cost and benefit of social effects, innovation and quality of life could not be quantified in the financial assessment. Generally, these criticism lead to understanding that it is essential to carry out VFM assessment for the whole lifecycle of PPP project by taken consideration of non-financial aspects and long term evaluation to better judge as to whether a PPP projects is successful.

\section{Research Methodology}

The particular research is exploratory in nature. According to Saunders et al. (2009), an exploratory study is a valuable means of finding out "what is happening", to seek new insights, to ask questions and to assess phenomena in a new light. Thus, this research is based on exploratory study which is motivated by the desire to better understand concept and principle of VFM for the PPP approach in Malaysia. To achieve this aim, it was decided that the survey strategy with the deductive approach was selected. It is a popular, common strategy and most frequently used to answer who, what, where and how of the questions which tends used for exploratory research. The survey research strategy provides a quantitative or numeric description of trends, attitudes or opinion of a population by studying a sample of population and analyse using descriptive and inferential analysis (Creswell, 2009). While, the positivism assumption was underpins the research strategy and methods choose in this research. The positivism assumption is referred to as scientific method which involves confirmation, falsification and commonly aligned with quantitative methods of data collection and analysis (Creswell, 2007 and Mackinzie \& Knipe, 2006). The quantitative perspective derives from a positivist epistemology which holds that there is an objective reality that can be expressed numerically. The quantitative perspective emphasizes studies that are experimental in nature; emphasize measurement and the search for relationship. In line with Amaratunga et al. (2002) quote that a quantitative research is concerned with defining an epistemological methodology for determining the truth-value of proposition and allows flexibility in the treatment of data in terms of comparative and statistical analysis of data collection. The questionnaire survey is used an effective method to seek a large sample size for quantitative data analysis (Dawson, 1999). The questionnaire is the broadest study, since VFM and PSC definition are varies between countries, thus on this huge undertaking and vast investigation, a questionnaire method was regarded as the most suitable method.

To obtain accurate and precise information, a purposive sampling technique was undertaken. There are several sample selection techniques in the construction and social science research environment. In essence, the sampling technique used for data collection for this research is a convenient sampling rather than random sampling. According to Babbie (2008), this type of sampling is a non-probability sampling that has not been selected using a random selection method. Essentially, this implies that some units in the population are more likely to be selected than the others. The reasons for using non-probability sampling are: the researchers understood that it was not feasible to contact the entire population; there was no sufficient information about the population and it was difficult to contact the selected sample through conventional probability sampling technique. Thus, the sampling technique was used in this study based on two main reasons. There is no comprehensive or any standard database of organisations in Malaysia that are involved in PPP/PFI projects. In addition, PPP/PFI procurement is a new concept and as a result of this, the number of organisations involved is growing but not in a form that means that the overall number of these organisations involved can be determined. As mentioned by Babbie (2008), to use random sampling would demand that the organisations involved being large and the population is known. The representative practitioners with vast experience in PPP were targeted which involved in development of UiTM campus in Malaysia. The purpose of the questionnaire was to ascertain the components utilized in development of PSC as a VFM assessment method. An empirical questionnaire survey was undertaken within the Malaysian PPP stakeholders for a period of four months from February to May 2010.The target respondents were selected based on their involvement with Malaysia PPP projects. The data was accumulated from 216 target respondents which comprised of top management levels of contractors, consultants and governments. They were chosen as they are the key stakeholders in PPP projects. The targeted respondents have vast knowledge and experiences in BOT and PPP projects local and abroad. A total of 51 respondents completed the questionnaires that were returned representing a response rate of $23.6 \%$. The descriptive analysis was adopted using the Statistical Package for Social Sciences (SPSS). The analyses primarily deal with the ranking of the variables, based on the mean values to determine their level of criticality.

\subsection{Findings and Discussion}

Literature place VFM as a process that should have continuity throughout the project lifecycle from the strategic formulation phase until completion stage. The lack of an explicit inclusion element in construction and completion 
stages of VFM assessment process makes it inappropriate for further consideration within this research. To assess the significance of the VFM philosophy, emphasis on both factors of non-financial and financial related aspects are paramount. Thus, the survey results had identified significant elements in each stage of PPP life cycle for a VFM assessment process. Table 1, 2, 3, 4 and 5 present the survey results on the aspects which showed high percentages to be considered in development of PSC as a VFM assessment method at each phase of PPP project life cycle (strategy formulation; procurement, construction and completion phase). The cut-off point for aspects viewed as important is those with a percentage of 50\% and above as suggested by Ismail (2009) and $\mathrm{Li} \mathrm{(2005).}$

\subsubsection{Financial Aspects in PSC}

In this study, the respondents' recorded all financial aspects are similar to be considered at each stage of PPP in VFM assessment process. Table 1 shows the five out of 9 aspects for financial assessment have the highest percentage that have been identified as the most important aspects in the formulation of PSC. Namely: Construction; maintenance \& operation cost; Life cycle cost; Discount rate used; future cash flow and risk calculation. All the five aspects indicated the highest scores for each phase. Thus it can be inferred that those aspects need to be incorporated during the development of PSC. Undeniably, financial aspect is the most important element used as a benchmark by decision makers in deciding to procure the PPP approach. This findings correlate with literary indicated that financial aspect is a significant element oblige at each stage of VFM assessment process. This is due for the fact that in justifying the VFM, financial assessment can provide a clearer picture in the aspects of cost savings and profit making out of the project and therefore can be used to convince decision makers. As mentioned by Broadbent and Gill (2002), an important issues to consider VFM when deciding to pursue the PPP projects is rest on the financial case.

Table 1. Financial aspects in PPP across project phases

\begin{tabular}{lllll}
\hline Financial aspects & \multicolumn{3}{c}{$\begin{array}{c}\text { PPP life cycle (1= strategy formulation; 2= procurement; 3= } \\
\text { construction; 4=operation) }\end{array}$} \\
\cline { 2 - 5 } & 1 & 2 & 3 & 4 \\
\hline 1. Construction, maintenance and operation cost & $76.5 \%$ & $78.7 \%$ & $80.5 \%$ & $84.8 \%$ \\
2. Life cycle cost & $74.5 \%$ & $75.6 \%$ & $79.5 \%$ & $82.6 \%$ \\
3. Discount rate used & $62.7 \%$ & $73.5 \%$ & $65.3 \%$ & $65.2 \%$ \\
4. Future cash flow & $60.8 \%$ & $59.9 \%$ & $60.6 \%$ & $62.3 \%$ \\
5. Risk calculation & $60.5 \%$ & $56.5 \%$ & $56.5 \%$ & $60.8 \%$ \\
\hline
\end{tabular}

Based on perusal of literature sources and guideline of VFM assessment from UK, Australia, Hong Kong, South Africa and British Colombia, all five aforementioned aspects are the most important aspects that must be taken into consideration in the calculation of PSC. This is because these aspects are closely related and give impact on the VFM calculation of any project. The PPP approach is a long term concept where VFM can only be ascertained based on a long term assessment. The analysis showed the majority of the respondents have a similar opinion on the construction, maintenance and operation cost as the most significant financial aspects to be integrated in PSC calculation.

This is supported by the review of the literature sources that reveal that the gist component of the PSC is the calculation of raw base cost. It represents a full estimate of all the costs include: Preliminary set up and planning works; construction cost; design and capital procurement, replacement; management and facility overheads; operating including maintenance cost. The second significant of financial aspects is life cycle cost (LCC). Principally, LCC is the term use to describe the consideration of all cost associated with a built asset throughout its life span of the projects. The cost includes: initial; operation and maintenance; replacements cost; adaptation cost and also demolition and recycling cost. According to Dallas (2006), for every unit spent on capital cost, five units are spent on maintenance; therefore any savings developed through LCC can be dramatic over the operating life of the asset. The third crucial financial aspects are discount rate used and future cash flow which are connected and influences each other. Overall, the survey respondents ranked discount rate used and future cash flow in 4th and 5th place respectively, implying that the two factors are significant to be integrated in the development of PSC. The probable explanation in regards to these aspects is due to opinion by other researchers and practitioners which claimed, the discount rate has a crucial impact on whether PPP projects offers better value for money than traditional systems. Additionally, the discount rate has an important impact into the preparation of the cash flow because the cash flow for a PPP project is spread more evenly over the life of the projects.

Thus, the difference becomes amplified in the net discounted costs with changes in the discount rate when cash flow is spread over a long period of time. Pollock et al. (2007) suggested the government's preferred VFM 
method which is expressed in a single rate known as the discount rate. By applying a discount rate to future payments a net present cost is obtained. Thus the net present value is derived by discounting future annual cash cost to reflect the achievement of VFM. Principally, under conventional approach the capital cost are accounted for during the construction period, rarely more than three years and have relatively higher net present value. However under PPP scheme, the cost is spread over 25 years and more distant payments have lower net present value.

While, the analysis shows future cash flow is also required for the development of PSC. A possible explanation with regards to this aspect is that PPP is a life cycle cost basis which is applied to increase the efficiency within the provision. According to Pollock et al. (2007), cash flow has to be forecasted reliably right from the design or planning phase. Value of the PPP is based on the projected growth of future cash flow. PPP can be truly mutually beneficial. Municipalities are able to monetize assets for upfront cash payments to funds future projects or inject additional capital in others while private owners, operators and investors are able to access the steady stream of cash flow produced. Thus, undoubtedly cash flow is crucial to be incorporated in the PSC development.The fifth of financial aspects chosen by the respondents is risk calculation. This finding to be fit with Pollock et al. (2007), mentioned the crucial aspects of PSC is the calculation of risk transfer. Fundamentally, most of the researchers such as Grimsey and Lewis (2005); Broadbent and Gill (2002); have a broad agreement on the importance of risk management in proving VFM of the PPP projects. As a neutral benchmark, PSC estimate will provide a rational basis to allocate the risk appropriately. As well as the financial costs of the scheme, the comparison includes the cost of some of the risks associated with the construction, maintenance and non-clinical services of the projects.

Thus, it can be concluded that the findings are matched with the literature such as Pollock et al.(2007) who claimed that two major items distinguish PPP from conventional method is the application of discount rate in cash flow and estimated value of risk transfer. The results could be incorporated in the development of PSC as a VFM assessment method, those financial aspects are significant. In line with the literature, the key elements of PSC including the following aspects: raw base cost; net present value number based on life cycle costing; risk adjusted, discount rate used; hypothetical and a forecast cash flow.

\subsubsection{Non-financial Aspects in PSC}

Despite the financial assessment constitutes a significant portion of the VFM analysis; it is not the sole factor driving in VFM of a project. Many practitioners argue to place equal importance on the non-financial aspects that affect the achievement VFM. For instance, in US the VFM analysis included both a financial and non-financial assessment (Morallos \& Amekudzi , 2010). Subsequently, Table 2 shows the results of eight (8) of non-financial aspects which had been declared by the respondents as the most significant aspects should be taken in strategy formulation phase. The aspects are: Project objectives; risk management; innovation; end user benefit; facilities management; contract duration \& residual value; environmental aspects and health and safety.

Table 2. Non- financial aspects: strategy formulation phase

\begin{tabular}{|c|c|}
\hline Non-financial aspects & $\%$ \\
\hline 1. Project objectives & $87.5 \%$ \\
\hline 2. Risk management & $78.6 \%$ \\
\hline 3. Innovation & $75.3 \%$ \\
\hline 4. User benefit & $72.3 \%$ \\
\hline 5. Facilities management & $68.9 \%$ \\
\hline 6. Contract duration \& residual value & $65.3 \%$ \\
\hline 7. Environmental aspects & $65.3 \%$ \\
\hline 8. Health \& safety & $58.6 \%$ \\
\hline
\end{tabular}

The findings are supported in the UK VFM guideline and Queensland VFM guideline which have written extensively about the non-financial aspects of VFM assessment. In the guideline, it is stated that it is crucial that VFM assessment be carried out in this to make an initial determination on the priority and affordability of the proposed projects. For instance, UK guideline states the need to assess the viability such as project objectives and flexibility of operation; desirability such as risk management; innovation and incentives \& monitoring; finally the achievability in terms of market interest; social benefit and environmental aspects. Hence all aspects such as environmental; social benefit; functionality; health \& safety; project objectives and facilities management must be assessed at this stage to ensure that the project will provide VFM for all the stakeholders. This is because the PPP approach is an approach that differs from the conventional approach where a project is given emphasis for a long term and involves future prediction. 
Moreover, table 3 presents the non-financial aspects to be integrated in the PSC during procurement phase. The respondents optimistically suggest ten (10) aspects to be considered at procurement phase. These are: facilities management; flexibility of operation; innovation; environmental aspects; contract duration and residual value; incentives \& monitoring; health \& safety; social benefit; end user benefit; and risk management. Noticeably the aspects chosen are the same ones at the strategy formulation phase except for project objectives that is not seen as important at this stage and with additional aspects such as social benefit; flexibility of operation and incentives \& monitoring. This is probably because the respondents are of the opinion that project objectives are only necessary to be valued and detailed at the stage of strategy formulation and not necessary to be evaluated at the proceeding stages. As of the strategy formulation phase, the aspects chosen at this stage show that wider factors need to be taken into account during the VFM assessment process that comprises the aspects of economy, efficiency and effectiveness of the projects. This is parallel with the arguments by Morallos \& Amekudzi (2010) that state that the criteria in PSC are poorly defined and do not even disclose the uncertainties involved in the calculation thus could be manipulated to obtain the desired results.

Table 3. Non- financial aspects: procurement phase

\begin{tabular}{ll}
\hline Non-financial aspects & $\%$ \\
\hline 1. Facilities management & $85.3 \%$ \\
2. Flexibility of operation & $75.1 \%$ \\
3. Innovation & $74.2 \%$ \\
4. Environmentala spects & $74.2 \%$ \\
5. Contract duration \& residual value & $72.6 \%$ \\
6. Incentives \& Monitoring & $68.7 \%$ \\
7. Health \& safety & $65.3 \%$ \\
8. Social benefit & $65.2 \%$ \\
9. End user benefit & $62.3 \%$ \\
10. Risk management & $59.7 \%$ \\
\hline
\end{tabular}

HM Treasury (2006), elaborates at the procurement stage the VFM assessment should focus on the effects of the whole projects conditions that could not be assessed during the financial assessment for instance environmental; social benefit; end user benefit and health \& safety issues. Moreover, they believed at this stage the VFM assessment should be looked in greater detail of the whole specific aspects and the characteristic of the projects. PSC is also seen as a tool that provides a financial analysis to support a non-financial analysis judgement of the best procurement option. Finding also contradicts the opinions of some researchers and practitioners who view PSC as a tacit assumption of the financial assessment only. One of the difficulties in listing elements of VFM at project construction stage is due to the lack of information as argued by Arbiyikli \& Eaton (2007). According to them the PPP literature has mostly focusing on examining VFM at the initial stage, while lacking on information at project construction and completion stage of the PPP. To a certain extent, no researcher or guidelines have ever covered elements for VFM assessment process at project construction stage. Nevertheless, the survey undertaken to determine the most significant of non-financial aspects associated in construction phase of VFM assessment process.

Table 4 presents eleven (11) non-financial aspects that have been chosen by most of respondents to be assessed in the construction phase. These are according to highest percentage: Innovation; facilities management; management of resource allocation; contract duration and residual value; environmental aspects; incentives \& monitoring; social benefit; end user benefit; asset utilisation; health \& safety and the lowest being risk management. Non-financial aspects for this stage are basically the same with the previous stage except for the flexibility of operation aspect that garnered a percentage of $45.6 \%$, and therefore deemed as less important. Two other aspects that garnered percentages above 50\% and therefore deemed important are asset utilisation and management of resource allocation. If perused, the aspects chosen comprise all important aspects that will have an impact on the economic; efficiency and the effectiveness of the projects that are in line with the definition of VFM as given by Khadaroo(2008); Arbiyikli \& Eaton (2007). For instance the environmental aspect, while conducting a VFM assessment it must be taken into consideration that the project must comply with and fulfil environmental policies and requirements in the form of air quality; climate change; sustainability and green building. 
Table 4. Non- financial aspects: construction phase

\begin{tabular}{|c|c|}
\hline Non-financial aspects & $\%$ \\
\hline 1. Innovation & $85.6 \%$ \\
\hline 2. Facilities management & $82.3 \%$ \\
\hline 3. Management of resource allocation & $74.8 \%$ \\
\hline 4. Contract duration \& residual value & $74.2 \%$ \\
\hline 5. Environmental aspects & $74.1 \%$ \\
\hline 6 Incentives \& Monitoring & $71.3 \%$ \\
\hline 7. Social benefit & $68.9 \%$ \\
\hline 8. End user benefit & $67.4 \%$ \\
\hline 9. Asset utilisation & $65.8 \%$ \\
\hline 10. Risk management & $62.5 \%$ \\
\hline 10. Risk management & $62.5 \%$ \\
\hline 11. Health \& safety & \\
\hline
\end{tabular}

This is clearly because VFM is not only assessed from the cost factor only but on the impact of the project on the environment. If the project has taken steps to ensure the environment is protected and enhancing the quality of life, therefore it can be said that the project provides VFM to the environment. Due to these reasons, it is crucial to carry out a VFM assessment process at construction phase to assess the environmental implications of a proposed strategic decision. It has been agreed that project's inability to meet environmental requirements can have an adverse impact on its financing efforts and may reduce the possibility to demonstrate VFM of the projects. This findings reflects to what Spiering (2006) mentioned that, in the Portugal, context environmental issues is one of the major elements there are necessitate in their VFM assessment process. Thus in conducting a VFM assessment, it is crucial to take into account all aspects stated that can give a broad definition of VFM.

Moreover, the contract duration and residual value is another aspect that has an impact on achieving VFM. For example: The UK VFM guideline state that: in setting the contract length it is important to do so with reference to the period over need for the service can reasonably predicted. It would be poor value if the service or mechanism suggested may change significantly due to demographics or technology change. This will have an effect on the VFM of the project. It is therefore important to integrate these aspects into the PSC which act as a VFM assessment method. On the other hand, at operation phase, most of the respondents believed twelve non-financial aspects as a significant to be integrated in PSC development. Table 5 shows those twelve (12) aspects including: enhance quality of life; facilities management; management of resource allocation; Innovation; environmental aspects; asset utilisation; social benefit; contract duration and residual value; end user benefit; flexibility of operation; incentives \& monitoring and risk management. Surprisingly, health \& safety that were considered important in the construction stage have been dropped in the operation stage with a percentage of only $43.6 \%$. Nevertheless, aspects enhance quality of life that was considered unimportant in the other phases have been selected as the most significant aspect for the operation phase. This may be because the respondents think that the VFM of the project can be clearly defined if the quality of life increases. For example, the construction of a UiTM campus indirectly has increased the infrastructure facilities of the area involved and can be utilised by the surrounding populace and at the same time also increase employment opportunities.

Table 5. Non- financial aspects: operation phase

\begin{tabular}{cc}
\hline Non-financial aspects & $\%$ \\
\hline 1. Enhance quality of life & $84.2 \%$ \\
2. Facilities management & $82.3 \%$ \\
3. Management of resource allocation & $73.3 \%$ \\
4. Innovation & $72.4 \%$ \\
5. Environmental aspects & $69.4 \%$ \\
6. Asset utilisation & $68.9 \%$ \\
7. Social benefit & $68.6 \%$ \\
8. Contract duration \& residual value & $67.6 \%$ \\
9. End user benefit & $67.4 \%$ \\
10. Flexibility of operation & $62.5 \%$ \\
11. Incentives \& Monitoring & $62.1 \%$ \\
12. Risk management & $58.9 \%$ \\
\hline
\end{tabular}


Thus, based on the finding, it clearly shows that the respondents agree that VFM must be seen from different and all angles of the projects that have a long term lifecycle. In line with statement by Yuan et al (2009), in PPP projects the best VFM should depends on the overall strategic plan in terms of environment, society, risk management; monitoring system; innovation and third party revenue. For instance, Carrillo et al. (2008) claimed innovation should be considered as important factors to demonstrate the VFM of the projects. Innovation is the way of applying new knowledge and technology in design, construction, services provided and resource allocation in order to improve performance. The innovation adopt is deem to reduce cost, time and risk of the projects and provide platform for technology transfer that is view as an effective factors to provide VFM of the projects. Thus, innovation must be included in the development of PSC and used in the VFM assessment of the projects.

Furthermore, to achieve VFM the incentives \& monitoring is also seen as an important aspect that is required to form PSC as argued by Yuan et al (2009). This is because it can be utilised to identify which processes and capabilities should be improved to become more competitive and which need to be maintained. It also help track whether the project process is delivering the values they were intended in providing value to the stakeholders. These incentives and monitoring may include indicators for environment, risk management, resource allocation and facilities management. It was clear from the findings show the significant financial and non-financial aspects should be embedded in the form of PSC. In conclusion, although the respondents believed the significance of the financial aspects, the overall findings shows the perception of respondents to include the non- financial aspects in the VFM assessment process as inevitable. This is important for the fact that the definition of VFM is a broad term that captures the issues of cost; quality; efficiency and effectiveness of the project.

\section{Conclusion}

VFM in PPP projects starts at the level of strategy formulation phase and is generated throughout the project cycle. VFM is the broad scope, thus it is crucial to ensure rigorous financial and non- financial elements are integrated in the VFM assessment process. In order to achieve the aim of the study, this research has ascertained various aspects both financial and non-financial to be integrated in the form of PSC as a VFM assessment method. From the findings it can be concluded that most of the respondents agreed in the assessment of VFM for projects it is crucial to take into consideration all angles that can leave a positive or negative impact on the success of the project that is being undertaken. This proven that most of the respondents believe VFM is not assessed based on lowest or cost saving but comprises the enhancement and benefit to the environment; innovativeness of the project; appropriate risk allocation; the society; end-users; resource allocation; asset utilisation and flexibility of operation. This finding is in line with the definition of VFM itself that has been explained by many researchers and practitioners. Therefore the government has to give more exposure to the stakeholders regarding the need to utilise PSC and to view VFM from all financial and non-financial angles. In conclusion, the development of a VFM assessment framework comprising both financial and on-financial aspects would facilitate a comprehensive dimension of VFM evaluation for PPP projects in Malaysia.

\section{References}

Akbiyikli. R., \& Eaton. D. (2008). A value for money framework proposal for PFI road projects.

Amaratunga. D., Baldry. D., Sarshar. M., \& Newton. R. (2002). Quantitative and qualitative research in the built environment: application of mixed research approach. Emarld, 51(1), 17-31.

Babbie. E. (2008). The basics of social research. Thompson Warsworth.

Broadbent. J., Gill. J., \& R. Laughlin. (2002). Evaluating the Private Finance Initiative in the National Health Service in the UK. Accounting, Auditing and Accountability Journal, 16(3), 95-114.

Carillo, P. M.., Robinson, H. S., Fole. P., Anumba, C. J., \& Bouchlaghem, D. (2008). Participation, barriers and oppurtunities in PFI: The United Kingdom experience. Journal of Management in Engineering (ASCE), 138-145. http://dx.doi.org/10.1061/(ASCE)0742-597X(2008)24:3(138)

Central Public Private partnership policy unit in the department of finance. (2007). Value for money and the Public Private Partnership procurement process. Dublin, Ireland National Development finance agency.

Creswell. J.W., \& Clark V. P. (2007). Designing and conducting: Mixed methods research. Sage Publications.

English, L., \& Guthrie, J. (2003). Driving privately financed projects in Australia:What makes them tick? $\begin{array}{lllll}\text { Accounting, Auditing \& } \quad \text { Accountability } & \text { Journal, }\end{array}$ http://dx.doi.org/10.1108/09513570310482354 
Grimsey, D., \& Lewis, M. K. (2005). Are Public Private Partnership Value for money? Evaluating alternative approaches and comparing academic and practitioner view. Accounting forum, (29), 345-378. http://dx.doi.org/10.1016/j.accfor.2005.01.001

HM Treasury. (2006). Value for money assessment guidance@ Crown copyright.

Hong Kong PPP guide. (2006). An introductory guide to Public Private partnership (PPPs). Constructing a Public sector Comparator (PSC). Annex D.

Ismail, S., \& Pendlebury. (2006). The Private Finance Initiative (PFI) in school: The experience of users. Financial Accountability and management, 381-404. http://dx.doi.org/10.1111/j.1468-0408.2006.00431.x

Ismail. F. (2009). A framework of the safety culture for the Malaysian construction organizations. Unpublished thesis.

Joaquim M. S. (2010). Do Public Private Partnerships create value for money for the public sector? The Portuguese experience. OECD Journal on Budgeting, (1).

Joaquim. M. S (2010). Do Public Private Partnerships create value for money for the public sector? The Portuguese experience. OECD Journal on Budgeting, (1).

Khadaroo. I. (2008). The actual evaluation of school PFI bids for value for money in the UK public sector. Critical Perspectives on Accounting, 19(8). http://dx.doi.org/10.1016/j.cpa.2007.05.001

Leigland, J., \& Shugart, C. (2006). Is the public sector comparator right for developing countries? Gridlines. Public private infrastructure advisory facility.

Li, B., Akintoye, A., Edwards. P. J., \& Hardcastle, C. (2005). The allocation of risk in PPP/PFI construction projects in the UK. International journal of Project management, 23, 25-35. http://dx.doi.org/10.1016/j.ijproman.2004.04.006

Mackenzie. N., \& Knipe. S. (2006). Research dilemmas: Paradigms, methods and methodology. Educational research, 16.

Morallos. D., \& A. Amekudzi. (2010). The state of the practice of value for money in comparing Public Private Partnership to Traditional Procurements. Public works management Policy, 13(14).

National Treasury South Africa. (2004). Public Private Partnership manual: Pretoria, South Africa: National Treasury PPP unit.

Ninth Malaysian Plan (9MP). (2006). Putrajaya: Prime Minister's Department. Retrieved August 17, 2006, from the World Wide Web: www.hm.treasury.gov.my

Partnership British Colombia. (2005). Project report: achieving value for Money Sea to sky highway improvement project.

Partnership Victoria. (2006). Department of treasury and finance, Victoria.

Pengeran.M.H., \& Wirahadikusumah. R. D (2010). Challenges in implementing the Public Sector Comparator for bid evaluation of PPP's infrastructure project investment. Proceeding of the First Makassar International Conference on Civil Engineering, March.

Pollock. A. M., Price. D., \& Player. S. (2007). An examination of the UK Treasury's evidence base for cost and time overruns data in UK value for money policy and appraisal. Public money and management, 127-134. http://dx.doi.org/10.1111/j.1467-9302.2007.00568.x

Queensland Government. (2008). Public Private Partnership guidance material.

Saunders. M., Lewis.P., \& Thornhill. A (2009). Research methods for business students (5 $5^{\text {th }}$ ed.). Prentice Hall.

Spiering. M.B., \& Dewulf. G. (2006). Strategic issues in Public Private Partnership: An International perspective. Blackwell publishing.

Yuan. Y.A., Zeng, Skbniewski. M.J., \& Q. Li. (2009). Selection of performance objective and key performance indicators in Public Private Partnership projects to achieve value for money, Construction management and economics, 27, 253- 270. 